\title{
Infection of Long-Term Tunneled Catheter for Hemodialysis: Impact of Prevention Protocols on the Rate of Infections and on Bacterial Ecology
}

\author{
A Guerraoui ${ }^{1}{ }^{3 *}$, B Roche ${ }^{3}$, A Plaidly ${ }^{2}$ and D Aguilera ${ }^{3}$ \\ ${ }^{1}$ Calydial Vienne, Centre Hospitalier de VICHY, France \\ ${ }^{2}$ Department of Bacteriology, Centre Hospitalier de VICHY, France \\ ${ }^{3}$ Department of Metabolism and Haemodialysis, Centre Hospitalier de VICHY, France
}

Submission: January 18, 2018; Published: February 09, 2018

*Corresponding author: A Guerraoui, Calydial Vienne, Centre Hospitalier de VICHY, France, Tel: + 33 (0) 428873800; Fax: 33(0)428873801;

Email: aguerraoui@gmail.com

\begin{abstract}
Background: Infection is the major source of morbidity and mortality among hemodialysis patients, mainly due to bacteremia associated to vascular access. Antimicrobial lock may induce emergence of resistant organisms.

Design: Observational cohort study.

Setting \& Participants: The study cohort comprised all prevalent adults treated with hemodialysis through a tunneled catheter from March 1, 1999, to December 31, 2008, in Vichy, France (31 536 catheter-days, 144 tunneled catheters, 102 patients).

Quality Improvement Plan: Universal hygienic rules, set-up of a follow-up registry, antimicrobial locks: heparin plus gentamicin (Period 1, March 99 - June 2000); heparin alone (Period 2, July 2000 - December 2004); citrate (Period 3, from January 2005 on).

Measures: Repeated observations of catheter-related bacteremia (CRB), catheter colonization and orifice infection, analyzed by using simple descriptive statistics, chi2 tests and Kaplan Meier tests.

Results: Gentamicin lock was associated with a reduction in CRB incidence from 1.96 to 0.29 per 1000 catheter-days ( $<<0.005)$, but with significant emergence of bacterial resistance $(\mathrm{p}<0.005)$. Heparin alone was associated with a decrease of resistance but a higher CRB incidence of 0.63 , despite reinforcement of hygienic rules. Citrate lock was associated with a CRB incidence of $0.28 / 1000$ catheter-days without any emergence of bacterial resistance. No adverse event or catheter thrombosis was observed for this period.
\end{abstract}

Limitations: This is an uncontrolled observational study and cannot prove causality, but the follow-up period of 9 years is long enough to provide a clear experience back-up.

Conclusion: Hygiene recommendations associated with citrate lock solution and thorough monitoring keep infection associated to hemodialysis at very low risk.

Keywords: Hemodialysis; Bacteremia; Gentamicin

Abbreviations: CRB: Catheter-Related Bacteraemia; HD: Haemodialysis; CNS: Coagulase-Negative Staphylococci

\section{Introduction}

The prevalence of haemodialysis is expected to annually increase by $4 \%$ due to increased life expectancy and progression of pathologies leading to renal failure [1]. Infection either localized or systemic, is the major source of morbidity and mortality among haemodialysis patients. Its incidence varies from 2.6 to 5.7 infections per 100 dialysis months [2,3]. The main source of these infections is bacteremia associated to vascular access, implied in 48 to $73 \%$ of them [4] and responsible for $26 \%$ of catheter withdrawals [5]. The incidence of catheterrelated bacteraemia (CRB) ranges from 0.65 to 5.5 per 1000 days of catheterization, depending on the type of catheter $[4,6,7]$, and is even higher for uncuffed catheter (3.8-12.8 events per 1000 catheter-days) than for tunneled-cuffed catheter $[7,8,9]$. The relative risk of bacteraemia is 7.64 fold higher in patients requiring catheter compared to those having a native arteriovenous fistula, as shown in a prospective study involving 988 end-stage renal disease patients [10].

Native arteriovenous fistula is the gold-standard vascular access for haemodialysis, nevertheless venous catheter use is 
widespread and remains the simplest and fastest mean to face haemodialysis urgency or difficulties of vascular access [11]. The catheter is a temporary or permanent alternative to vascular access when arterio-vascular status prevents the creation of an arteriovenous fistula (diabetes, age, arterial calcification).

The optimal intervention for reducing catheter-related infections is to reduce to less than $10 \%$ the number of patients dependent on central venous catheters [12]. However, there will always be a proportion of patients who require catheters and who will remain susceptible to these infections. Reduction of these infections implies several techniques, including universal hygiene rules, catheter design, use of antimicrobial impregnated catheters, use of tunneled-cuffed catheters, local topical treatments, nasal carriage eradication, and use of antimicrobial lock solutions.

On March 1999, we observed an incidence of 1.96 CRB per 1000 catheters-days. In order to decrease this incidence, we set up a reinforced protocol to monitor all catheter-related haemodialysis procedures, regarding hygiene recommendations, use of lock solutions and setting a follow-up registry with systematic culture of stagnation fluid and monthly evaluation of bacteriological results (CRB, orifice infection, microbial colonization).

We started a prospective evaluation of our quality procedures in clinical and hygiene practice. We present the results of more than 8 years of follow-up evaluating measures and optimal actions to get the lowest incidence of CRB.

\section{Materials and Methods}

\section{Study population}

This prospective study was performed in the Renal-Metabolic Department at Vichy Hospital, France. There were 88 patients on dialysis therapy, 64 treated with haemodialysis (HD) and 24 with peritoneal dialysis. HD was performed thrice weekly using Fresinus 4008 machinery, with bicarbonate-based dialysate and synthetic high-flux hemodialyzers. All HD sessions were of 4 hours duration.

All catheters were uncuffed tunneled; they were inserted percutaneously on preferably the right jugular vein, according to Bernard Cannaud technique [13] and without prior prophylactic antibiotherapy. Catheters were inserted by a nephrologist, in a surgery room with maximal sterile barrier precautions and without ultrasound guidance. Prevalent catheter use ranged between $16 \%$ and $20 \%$ during the study period.

\section{Data collection}

Data collected included age, sex, diabetes, orifice infection, colonization and catheter-related bacteremia. The emergence of staphylococcus epidermidis resistance (MRSE) was assessed by the rates of gentamicin, methicillin, quinolone, and vancomycin resistance. Catheter characteristics included the type of catheter, the number of inserted catheters, duration of placement and reason for catheter removal (catheter no longer needed, use of a fistula, transplantation, infection and patient death).

\section{Intervention}

A reinforcement of universal hygiene rules, following the 1996 guideline for prevention of intravascular device-related infections [14], included a designated trained personnel and procedures for catheter connection-disconnection to be performed by two nurses:

o Use of sterile kits specific to the centre, with a defined number of gloves, compresses, blouses, helmets ...;

o One nurse is dressed with sterile blouse, mask, helmet, gloves and is in charge of all cleaning and connectingdisconnecting procedures. Gloves are to be changed each time the machinery is touched; the other nurse wears sterile gloves, helmet and mask and is in charge of the machinery and in providing the material to the first nurse;

o Connection using a specific sterile kit, in two steps: cleaning of orifice and dressings, using sodium hypochlorite $0.5 \mathrm{~g} / 100 \mathrm{~mL}$; aspiration of stagnation fluid then connection;

o Disconnection using a specific sterile kit.

o Every month there is a sampling of catheter lock solution before HD session for bacteriological culture.

Three types of lock solution have been used:

o $\quad$ Period 1 (P1) (March 1999 to June 2000) gentamicinheparin lock solution (heparin $5000 \mathrm{UI} / \mathrm{ml}$, gentamicin $2 \mathrm{mg}$ / $\mathrm{ml})$.

o $\quad$ Period 2 (P2) (July 2000 to December 2004) heparin alone lock solution (heparin 5000UI/ml).

o $\quad$ Period 3 (P3) (January 2005 - on going) citrate lock solution (citrate $46.7 \mathrm{mg} / \mathrm{ml}$ ).

From January 2003 on, a hygiene-specialized nurse realized every six months an audit of our quality procedures in clinical and hygiene practice. The follow-up registry allowed for periodical re-evaluation of our procedures and for corrective actions to be taken.

\section{Microbiological techniques}

Catheter: seeding using Brun-Buisson method. The catheter tip is put in $1 \mathrm{ml}$ of sterile physiological water and vortexed. A sampling of $100 \mu \mathrm{L}$ is then seeded in streak on blood agar plates. After 24 to 48 hours, colonies are counted. Positivity threshold is $103 \mathrm{CFU} / \mathrm{mL}$.

Catheter orifice: Samplings on swab are seeded in streak on blood agar plate. Stagnation fluid is directly seeded on blood culture vials (BioMérieux aerobic vials) in the Renal Metabolic department, and then incubated 6 days in Bact'Alert 3D controller (BioMérieux). 
Standard microbiological methods were used to identify the colonizing/infecting organisms.

\section{Definitions}

CRB, the primary outcome in our study, is defined as the isolation of the same phenotypic microorganism from both peripheral-blood culture and orifice infection or catheter lock solution, with clinical and biological signs of infection (fever > $38{ }^{\circ} \mathrm{C}$, chills, systolic blood pressure $<90 \mathrm{mmHg}$, leukocytosis/ leucopenia) with compeling evidence of catheter as the only source.

Catheter colonization is defined as the isolation of a microorganism in the catheter lock solution without CRB.

Infection of the orifice is defined as the isolation of a microorganism in the orifice catheter with clinical signs of infection (orifice inflammation, purulent flow) without CRB.

\section{Statistical analysis}

Patient characteristics were expressed by descriptive statistics.

Colonization and CRB rate were expressed by using cumulative incidences and incidence densities. Cumulative incidences were expressed as percentage, and incidence densities, per 1000 catheter-days. Categorical variables were compared by using Chi2 test. Kaplan-Meier test was used to compare survival catheters in the three periods.

\section{Results}

The cohort consisted in 102 patients representing a total of 144 non-cuffed tunneled catheters. Patients' characteristics are listed in Table 1 . The population was aged $69.2 \pm 16$ years, $63.5 \%$ were male and $41.5 \%$ had diabetes. The study included 31536 catheter-days. Overall, we observed 21 (14.6\%) CRB, representing 0.66 per 1000 catheter-days, 100 (69.4\%) catheter colonized representing 1.2 per 1000 catheter-days and 122 (84\%) orifice infection representing 6.01 per 1000 catheter-days (Table 2 \& 3).

Table 1: Patients characteristics.

\begin{tabular}{|c|c|c|c|c|}
\hline & ALL & Period 1 & Period 2 & Period 3 \\
\hline Number* & 102 & 23 & 55 & 43 \\
\hline Age (years) & $69.2 \pm 16$ & $66.9 \pm 21.3$ & $68.98 \pm 14.9$ & $70.39 \pm 15.96$ \\
\hline Men & $63.5 \%$ & $60.9 \%$ & $53.9 \%$ & $67.2 \%$ \\
\hline Diabetes & $41.5 \%$ & $39.1 \%$ & $38.2 \%$ & $46.6 \%$ \\
\hline
\end{tabular}

Table 2: Catheter characteristics.

\begin{tabular}{|c|c|c|c|c|}
\hline & ALL & Period 1 & Period 2 & Period 3 \\
\hline Number* & 144 & 23 & 76 & 58 \\
\hline Catheter-days & 31536 & 4163 & 12543 & 14830 \\
\hline Mean catheter & 200.81 & 181 & 165.64 & 255.7 \\
\hline Day exposure & (3 to 1215) & (5 to 484) & (3 to 843) & (6to1215) \\
\hline
\end{tabular}

* Catheters could belong to several periods

Table 3: Measurements and Outcomes of catheter-related bacteremia, colonized catheters and orifice infection.

\begin{tabular}{|c|c|c|c|c|}
\hline & ALL & Period 1 & Period 2 & Period 3 \\
\hline Catheter-days & 31536 & 4163 & 12543 & 14830 \\
\hline \multicolumn{5}{|c|}{ Catheter Related Bacteremia } \\
\hline Cumulative incidence & $21(14,6 \%)$ & $5(21.7 \%)$ & $11(14.4 \%)$ & $5(8.6 \%)$ \\
\hline $\begin{array}{c}\text { Incidence density } \\
\text { (per } 1000 \text { catheter-days) }\end{array}$ & 0.66 & 1.2 & 0.88 & 0.34 \\
\hline \multicolumn{5}{|c|}{ Catheter Colonization } \\
\hline Cumulative incidence & $100(69.4 \%)$ & $44(191 \%)$ & $32(42.1 \%)$ & $\begin{array}{c}24 \\
(41.3 \%) \\
\end{array}$ \\
\hline $\begin{array}{c}\text { Incidence density } \\
\text { (per } 1000 \text { catheter-days) }\end{array}$ & 3.27 & 9.85 & 2.55 & 1.62 \\
\hline \multicolumn{5}{|c|}{ Orifice Infection } \\
\hline Cumulative incidence & $122(84 \%)$ & $25(108.7 \%)$ & $62(81.5 \%)$ & $34(58.6 \%)$ \\
\hline $\begin{array}{c}\text { Incidence density } \\
\text { (per } 1000 \text { catheter-days) }\end{array}$ & 3.86 & 6.04 & 4.94 & 2.29 \\
\hline
\end{tabular}


*per 1000 catheter-days

tincrease due to one diabetic patient who presented twice a bacteremia and a furonculosis

Table 4: Overall incidence of catheter-related infections: bacteremia and colonized catheters.

\begin{tabular}{|c|c|c|c|c|c|c|c|c|c|c|}
\hline & \multicolumn{2}{|c|}{$\begin{array}{c}\text { Gentamicin + } \\
\text { Heparin }\end{array}$} & \multicolumn{4}{|c|}{ Gentamicin + Heparin } & \multicolumn{4}{|c|}{ Citrate } \\
\hline $\begin{array}{c}\text { Lock } \\
\text { solution }\end{array}$ & \multicolumn{2}{|c|}{4954 catheter-days } & \multicolumn{4}{|c|}{12405 catheter-days } & \multicolumn{4}{|c|}{11729 catheter-days } \\
\hline Period & 1 & & \multicolumn{2}{|c|}{$2 \mathrm{a}$} & \multicolumn{2}{|c|}{$2 b$} & \multicolumn{4}{|c|}{3} \\
\hline Year & 1999 & 2000 & 2001 & 2002 & 2003 & 2004 & 2005 & 2006 & 2007 & 2008 \\
\hline \multicolumn{11}{|c|}{ Orifice } \\
\hline Infection* & 5.22 & 3.76 & 5.07 & 5.28 & 3.78 & 6.95 & 3.86 & 2.08 & 1.27 & 1.93 \\
\hline Bacteremia* & 1.96 & 0.29 & 0.39 & 2.03 & 0.76 & 0.63 & 0.28 & 0.30 & $0.63 \dagger$ & 0 \\
\hline
\end{tabular}

Period 1 included 23 patients, representing 23 non-cuffed tunneled catheters. The population was aged $66.9 \pm 21.3$ years, $60.9 \%$ were male and $39.1 \%$ had diabetes. The mean catheter day exposure was 181 days (5 to 484), representing 4163 catheter-days. The

CRB for this period was 5 (21.7\% and 1.2 per 1000 catheterdays). There was 44 catheters colonized (191\% and 9.85 per 1000 catheter-days), and 25 orifice infections (108.7\% and 6.04 per 1000 catheter-days).

Period 2 included 55 patients, representing 76 non-cuffed tunneled catheters. The population was aged $68.98 \pm 14.9$ years, $53.9 \%$ were male and $38.2 \%$ had diabetes. The mean catheter day exposure was 165.64 days (3 to 843), representing 12543 catheters-days. The CRB for this period was 11 (14.4\% and 0.88 per 1000 catheter-days). There was 32 catheters colonized (42.1\% and 2.55 per 1000 catheter-days) and 62 orifice infections (81.5\% and 4.94 per 1000 catheter-days).
Period 3 included 43 patients, representing 58 non-cuffed tunneled catheters. The population was aged $70.39 \pm 15.96$ years, $67.2 \%$ were male and $46.6 \%$ had diabetes. The mean catheter day exposure was 255.7 days (6 to 1215), representing 14830 catheters-days. The CRB for this period was 5 (8.6\%\% and 0.34 per 1000 catheter-days). There was 24 catheters $(41.3 \%$ and 1.62 per 1000 catheter-days) and 34 orifice infections (58.6\% and 2.29 per 1000 catheter-days).

The overall results of the study is summarized Figure 1, showing the different study periods altogether with CRB and gentamicin-multiresistant staphylococcus epidermidis. Table 4 displays the bacteriological follow-up across all periods of the study.

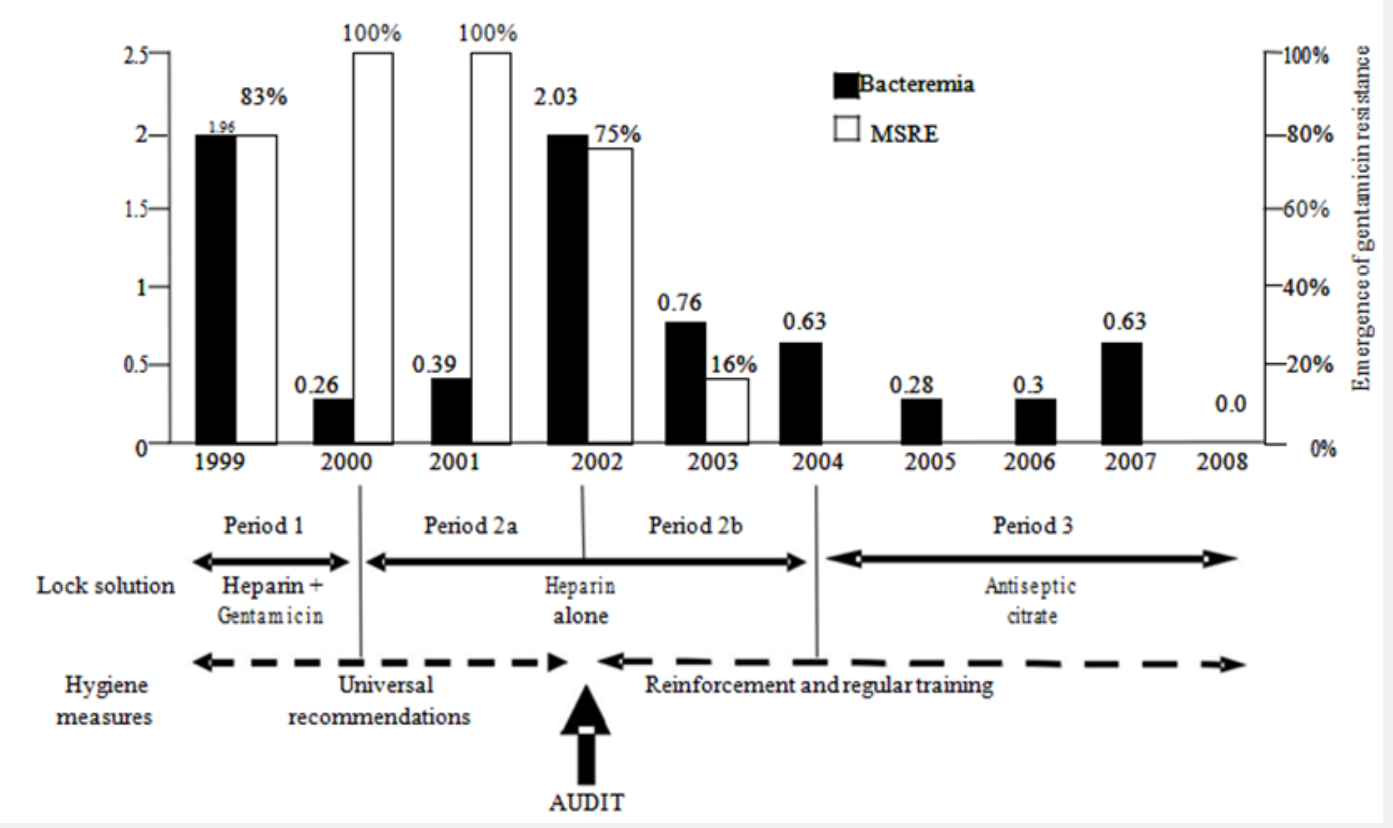

Figure 1: Strategies applied for prevention of infections, according to catheter-related bacteremia and emergence of gentamicin resistance. The audit that took place in December 2002 defines 2 sub-periods (2a and 2b) during Period 2 
The gentamicin lock solution (Period1) allowed decreasing the CRB incidence from 1.96 to 0.29 per 1000 catheters-days $(p<0.005)$, the orifice infection to 3.76 catheters-days and the microbial colonization to 3.4 catheters-days. However, antibiotic lock solution generated a significant $(\mathrm{p}<0.005)$ emergence of bacterial resistance to antibiotics. A $83 \%$ resistance to gentamicin was already noted in 1999, which increased to $100 \%$ in June 2000, while resistance to methicillin was $50 \%$ in 1999 , increasing to $80 \%$ in 2000 .

In 2000 (period 2), the antibiotic lock was discarded to only keep universal hygiene rules and a heparin-alone lock from July 2000. The MRSE rate decreased within the next 18 months, and return back to the initial bacteriological situation 30 months later (Figure 2).

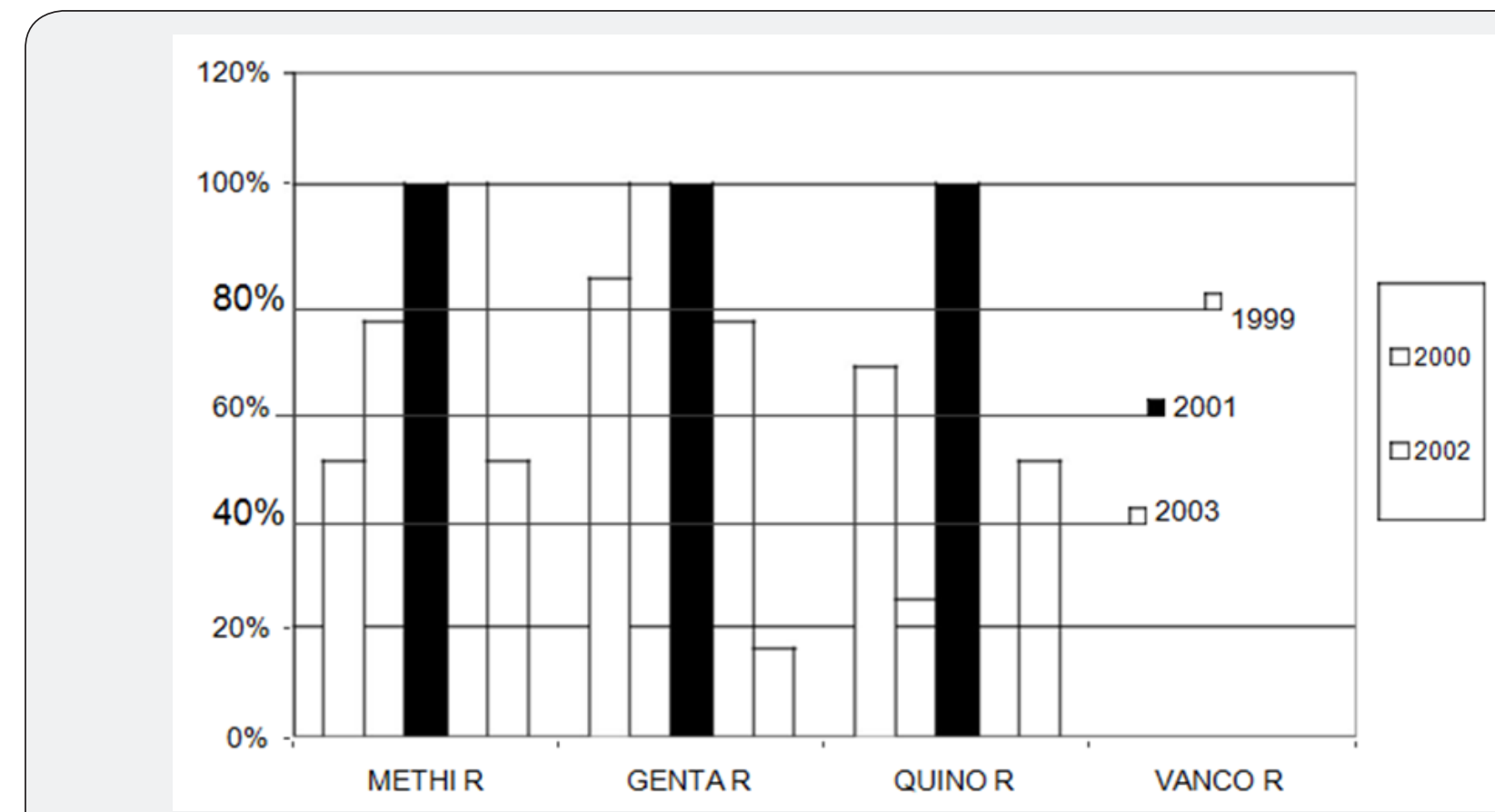

Figure 2: Progression of Multiresistant Staphylococcus Epidermidis Emergence (MRSE) between 1999 and 2003.

Appearance of Multiresistant Staphylococcus Epidermidis after use of antibiotic lock solution (gentamicin). The multiresistant were tested with different types of antibiotics: methicillin (methi R), gentamicin (genta R), Quinolone (quino R), and vancomycin (Vanco R)) from 1999 to 2003 .

During the second period of the study (July 2000 to December 2004), the incidence of catheter-related bacteremia increased from 0.39 in 2001 to 2.03 per 1000 catheter-days in 2002 (Period 2a). An audit of hygiene practices revealed breakages in the universal hygiene recommendations by the youngest nurses. Therefore the procedure included an intensive nurse training and a 6-monthly follow-up of the nursing staff by a hygiene specialized nurse. The incidence of bacteremia decreased to 0.76 and 0.63 per 1000 catheter-days in 2003 and 2004 respectively (Period 2b).

However, incidence of CRB was still greater than that obtained after antibiotic lock solution (respectively 0.63 and 0.28 per 1000 catheters-days respectively), and we observed an increase in orifice infection from 3.78 to 6.95 per 1000 catheters-days. If the association of heparin lock solution and the practice of hygiene recommendations improved the incidence of CRB, a bacterial biofilm persisted on the internal surface of the catheter, which facilitates adhesion and colonization and bacterial resistance.

In 2005 (period 3), the heparin lock solution was replaced by an antiseptic/anticoagulant lock solution (citrate lock solution $46.7 \mathrm{mg} / \mathrm{ml}$ ) in order to obtain a low level of CRB without the disadvantages of antibiotic lock solution (MRSE) and heparin lock solution (Biofilm catheter formation). The incidence of CRB decreased from 0.37 to 0.28 per 1000 catheter-days and was eventually null in 2008. The target low level of CRB was reached. No adverse events and no catheter thrombosis were observed.

The infection rates according to study periods were 1.2 (P1), 0.88 (P2; 0.92 for P2a; 0.83 for P2b) and 0.34 per 1000 catheterdays (P3), with an overall infection rate of 0.67 per 1000 catheterdays. As seen in Figure 3, the Kaplan-Meier comparison showed no difference in cumulative survival of catheters according to periods. It can be concluded that antibiotic locks provide no advantages as compared to Universal Hygiene Rules, which have the additional superiority of respecting bacterial ecology and avoid resistance emergence. 


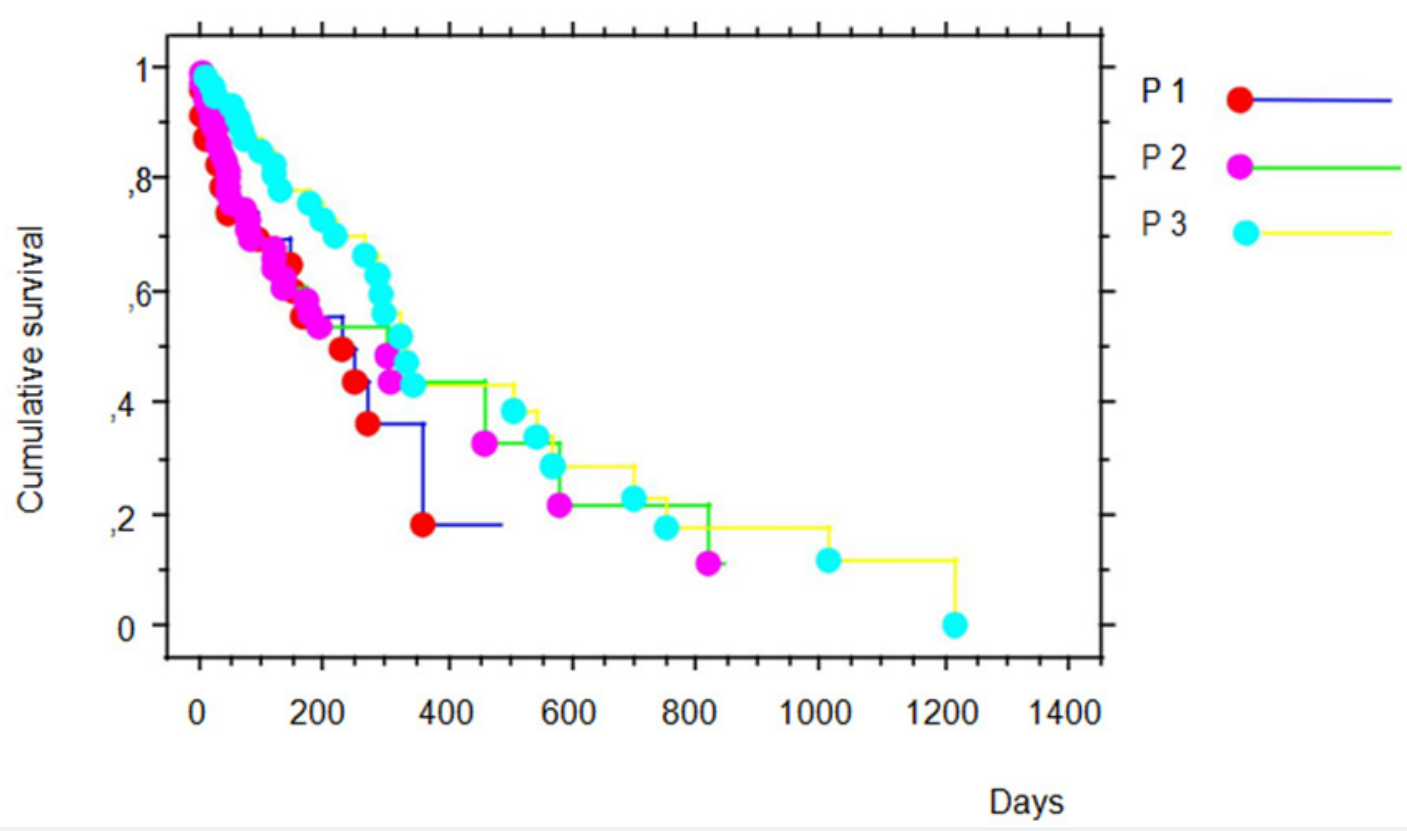

Figure 3: Kaplan-Meier Survival curve of catheters according to the period of the study (days).

\section{Discussion}

Infectious complications of vascular access are the major source of morbidity and mortality among haemodialysis patients. The prevention of infections could be assumed by a prophylaxis associating the respect of hygienic recommendations and surveillance and control of infection. We investigate a prospective study to evaluate this prophylaxis further to a high level of infection in our haemodialysis unit. The efficiency of this prophylaxis was evaluated by a monthly monitoring of CRB incidence.

In order to decrease the bacteremia detected in our unit, we have used antibiotic lock solution (gentamicin and heparin). According to Kim et al. [15], the use of antibiotic lock solution (heparin and gentamicin or cefazolin) compared to lock solution without antibiotic (heparin alone), resulted in considerable reduction of incidence of CRB ( 0.44 events per 1000 catheterdays vs. 3.12 events per 1000 catheter-days). Many investigators have selected gentamicin as an antibiotic for preventing CRB, Kim [15] used gentamicin $(5 \mathrm{mg} / \mathrm{ml})$ associated to cifazol $(10 \mathrm{mg} / \mathrm{ml})$ and heparin $(1000 \mathrm{U} / \mathrm{ml})$, Dogra et al. [16] used gentamicin combined with citrate and Mc Intyre et al. [17] compared gentamicin associated to heparin to heparin alone. All these studies concluded to positive action of gentamicin lock solution on incidence of CRB, as observed in our series. As in all these studies, we observed the same action of gentamicin on the incidence of CRB, which reached its lowest level 15 months after implementation of our antibiotic lock solution (from 1.99 events per 1000 catheter-days at the beginning to 0.29 events per 1000 catheter-days after). However the other studies did not detect adverse effects, such as MRSE or increased complications with the use of antibiotic lock solution [18]. The limited followup of the studies do not exclude the onset of adverse events or bacterial resistance with longer use of antibiotic lock solution. Katneni et al in their study noted that chronic use of antibiotic lock solution could induce an emergence of antibiotic resistant organisms [19]. Studies using antibiotic lock solution were short-term studies (3 to 12 months) while in our study the period was longer than 12 months. A meta-analysis of all prospective randomized studies that compared antibiotic lock solution to heparin confirmed that antibiotic locking solutions reduce the catheter-related infections without significant side effects, but outlined an important limitation, namely the relatively short duration of follow-up of the studies which does not allow complete reassurance regarding the development of antibiotic resistance [20]. In an editorial to this meta-analysis, Allon acknowledged this limitation and expressed an important concern regarding the use of antibiotic locks [21]. More recently, Abbas et al. reported the emergence of gentamicin-resistant coagulase-negative staphylococci following the use of heparingentamicin lock [22]. Similarly, Landry reported the emergence of gentamicin resistance in his 4 years series of dialyze with a gentamicin lock initiated to decrease the incidence of catheterrelated infections. This emergence led to discard this type of lock and Landry recommend a special vigilance with long-term use of antibiotic-lock [23].

The first conclusion is that long-time antibiotic lock solution is a feature to induce emergence of antibiotic resistant organisms. To prevent this MRES, we decided to discard the antibiotic in lock solution, associated with the strict respect of hygiene recommendations. Antibiotic lock solution was replaced 
by heparin lock solution to prevent thrombosis in catheter. The incidence of CRB was constant excepted in 2002 where it reached a high level. Further to this, an audit was realized by a hygiene nurse. The actions have been intensification of hygiene recommendations, training of the nursing staff and monitoring of hygiene recommendations every six months. All these actions allowed decreasing strongly the incidence of CRB from 2.03 to 0.63 events per 1000 catheter-days. This experience confirms the conclusion of Bearthard et al. [24] which show that the strict respect of the standards of hygiene can reduce considerably the incidence of CRB. Moreover, Hajjar et al in their study concerning surveillance of infection in several centers emphasized the importance of hygiene standard recommendations and their impacts on decrease of infection in haemodialysis center despite the presence of others infection risk factors $[3,6]$. Although there was a decrease in the incidence of CRB, we observed a bacterial biofilm formation. The bacterial biofilm is known as a source for bacteremia and to promote formation of bacterial resistance. We have looked for an alternative lock solution having an anticoagulant effect. In the US, as the most widely used anticoagulant catheter lock solution is sodium heparin, studies examine the effect of several alternative catheter lock solutions on in vitro biofilm formation by laboratory and clinical isolates of S. aureus and coagulase-negative staphylococci (CNS). It was demonstrated that sodium citrate at concentrations above $0.5 \%$ efficiently inhibits bacterial biofilm formation and cell growth of S. aureus and Staphylococcus epidermidis [25]. Several experiments demonstrated that trisodium citrate $(30 \%)$, citrate $(4 \%)$ and taurolidine $(1.35 \%)$ solutions are effective and safe for the prevention of CRB, while heparin stimulates bacterial biofilm catheter formation. In addition to its anticoagulant effect, an antimicrobial concentration-dependant effect of citrate is observed. At concentrations of $2 \%$ or lower the antimicrobial effect is low, whereas at concentrations $2.2 \%$ $15 \%$ an antimicrobial effect to Gram Positive organisms is observed. At the concentration of $30 \%$ citrate has bactericide properties as observed by Weijmer [25]. This property can be increased by addition of gentamicin, vancomycin, or cefazolin. As a high concentration of trisodium citrate provides local anticoagulation effect, it had been advocated as catheter lock solution. However high concentration of citrate in clinical practice was little investigated, and its efficacy and safety has yet not been established [25-27]. Citrate offers several clinical advantages over concentrated heparin: it avoids heparinassociated bleeding complications, and provides an effective alternative for patients with suspected or confirmed heparininduced thrombocytopenia [28]. Some showed the preventive effect of the gentamicin citrate mixture on the incidence of CRB in patients with tunneled cuffed catheters, others confirmed the compatibility of ethanol and $4 \%$ trisodium citrate for potential use as a catheter locking solution. Flushing of an ethanol solution trough an intravascular device is likely to be convenient and to have limited side effect [29]. This study confirmed eradication of microorganisms after $1 \mathrm{~h}$ contact with ethanol-citrate lock solution [30]. Recent studies reported that locking the catheter with an ethanol solution may be of value as an adjunct to the treatement of intrascular device-related bloodstream infection [29] and to prevent recurrent catheter related sepsis [30,31]. The ethanol lock solution can prevent and eradicate biofilm in vitro [32,33]. Betjes et al. [34] demonstrated that a taurinebased antiseptic locking solution was effective for preventing catheter-related sepsis [34]. The association of taurolidin citrate would seem to be interesting for a near future. Indeed no biofilm formation is observed with taurolidin, neither emergence of resistance. It seems to be effective with a concentration of $4 \%$ citrate and $1.35 \%$ taurolodin.

This study confirms that hygiene recommendations associated with a surveillance of infection by routine measurement of CRB incidence are able to control the risk of infection and to avoid MRSE and bacterial biofilm formation. We have observed that primary feature of surveillance and control is able to keep a low level of incidence of infection in haemodialysis at the long-term. Today we continue with this protocol and we still have a low level of infection, reaching even zero for 2008.

\section{Acknowledgment}

The authors thank Pr Bertrand SOUWEINE for help preparing the manuscript.

\section{References}

1 Jungers P, Robino C, Choukroun G, et al. (2001) Evolution de l'épidémiologie de l'insuffisance rénale chronique et prévision des besoins en dialyse de suppléance en France. Néphrologie 22: 91-97.

2 Kaplowitz LG, Comstock JA, Landwehr DM, Dalton HP, Mayhall CG (1988) A prospective study of infections in haemodialysis patients: patient hygiene and other risk factors for infection. Infect Control Hosp Epidemiol 9(12): 534-541.

3 Hajjar J (2000) Surveillance des infections chez les hémodialysés chroniques dans 6 centre de la Région Rhone Alpes. Hygiene's IX: 255262 .

4 Nassar GM, Ayus JC (2001) Infectious complications of the haemodialysis access. Kidney Int 60(1): 1-13.

5 Lavigne T, De Almeida N, Meunier O, Petitjean P, Hannedouche T (2001) Preliminary results of a prospective study on predictive factors for infection linked to central venous catheters of haemodialysis. Nephrologie 22(8): 407-408.

6 Hajjar J, Girard R, Marc JM, Ducret L, Beruard M, et al. (2004) Surveillance des infections chez les hémodialysés chroniques en centre. Néphrologie 25: 133-140.

7 Taylor G, Gravel D, Johnston L, Embil J, Holton D, et al. (2002) Prospective surveillance for primary bloodstream infections occurring in Canadian haemodialysis units. Infect Control Hosp Epidemiol 23: 716-720.

8 Weijmer MC, Vervloet MG, ter Wee PM (2004) Compared to tunneled cuffed haemodialysis catheters, temporary untunnelled catheters are associated with more complications already within 2 weeks of use. Nephrol Dial Transplant 19: 670-677.

9 Tokars JI, Miller ER, Stein G (2002) New national surveillance system or haemodialysis associated infections: initial results. Am JInfect Control 30: 288-295. 
10 Hoen B, Paul-Dauphin A, Hestin D, Kessler M (1998) EPIBACDIAL: a multicenter prospective study of risk factors for bacteremia in chronic hemodialysis patients. J Am Soc Nephrol 9(5): 869-876.

11 Legendre C, Saltiel C (1994) National survey on temporary vascular access for haemodialysis. Nephrologie 15(2): 61-63.

12 (2001) K/DOQI Clinical Practice Guidelines for Vascular Access: Update 2000. Am J Kidney Dis 37(Suppl 1): S137-181.

13 Canaud B, Beraud JJ, Joyeux H, Mion C (1986) Internal jugular vein cannulation using 2 silastic catheters. A new, simple and safe longterm vascular access for extracorporeal treatment. Nephron 43(2) 133-138.

14 Pearson ML (1996) Guideline for prevention of intravascular devicerelated infections. Part I. Intravascular device-related infections: an overview. The Hospital Infection Control Practices Advisory Committee. Am J Infect Control 24: 262-277.

15 Kim SH, Song KI, Chang JW, Kim SB, Sung SA, et al. (2006) Prevention of uncuffed haemodialysis catheter-related bacteremia using an antibiotic lock technique: a prospective, randomized clinical trial Kidney Int 69: 161-164.

16 Droga GK, Herson H, Hutchison B, Irish AB, Heath $\mathrm{CH}$, et al. (2002) Prevention of tunneled haemodialysis catheter-related infections using catheter filling with gentamicin and citrate: randomized controlled study. J Am Soc Nephrol 13(8): 2133-2139.

17 McIntyre CW, Hulme LJ, Taal M, Fluck RJ (2004) Locking of tunneled haemodialysis catheters with gentamicin and heparin. Kidney Int 66(2): 801-805

18 Korbila IP, Bliziotis IA, Lawrence KR, Falagas ME (2007) Antibioticlock therapy for long-term catheter-related bacteremia: a review of the current evidence. Expert Rev Anti Infect Ther 5(4): 639-652.

19 Katneni R, Hedayati (2007) Central venous catheter-related bacteremia in chronic haemodialysis patients: epidemiology and evidence-based management. Nat Clin Pract Nephrol 3(5): 256-266.

20 Jaffer Y, Selby NM, Taal MW, Fluck RJ, McIntyre CW (2008) A Metaanalysis of Hemodialysis Catheter Locking Solutions in the Prevention of Catheter-Related Infection. Am J Kidney Dis 51(2): 233-241.

21 Allon M (2008) Prophylaxis Against Dialysis Catheter-Related Bacteremia: A Glimmer of Hope. Editorial. Am J Kidney Dis 51(2): 165168.

22 Abbas SA, Haloob IA, Taylor SL, Curry EM, King BB, et al. (2009) Effect of antimicrobial locks for tunnelled hemodialysis catheters on bloodstream infection and bacterial resistance: a quality improvement report. Am J Kidney Dis 53(3): 492-502.

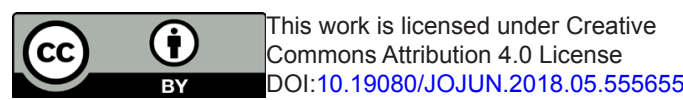

23 Landry DL, Sweet SJ, Gobeille SL, Haessler SD, Vaidya CK, et al. (2009) Long-Term Gentamicin Lock Catheter Prophylaxis is Associated with Gentamicin-Resistant Gram-Positive Bacteremias in Chronic Hemodialysis Patients [ASN 2009 abstract F-FC301].

24 Beathard GA (2003) Catheter management protocol for catheterrelated bacteremia prophylaxis. Semin Dial 16(5): 403-405.

25 Weijmer MC, van den Dorpel MA, Van de Ven PJ, ter Wee PM, Groeneveld JO, et al. (2005) Randomized clinical trial comparison of trisoium citate $30 \%$ and heparin as catheter-locking solution in haemodialysis patients. J Am Soc Nephrol 16: 2769-2777.

26 Mandolfo S, Borlandelli S, Elli A (2006) Catheter lock solutions: it's time for a change. J Vasc Access 7(3): 99-102.

27 Stas KJ, Vanwalleghem J, De Moor B, Keuleers H (2001) Trisodium citrate $30 \%$ vs. heparin $5 \%$ as catheter lock in the interdialytic period in twin- or double-lumen dialysis catheters for intermittent haemodialysis. Nephrol Dial Transplant 16(7): 1521-1522.

28 Grudzinski L, Quinan P, Kwok S, Pierratos A (2007) Sodium citrate 4\% locking solution for central venous dialysis catheters--an effective, more cost-efficient alternative to heparin. Nephrol Dial Transplant 22(2): 471-476.

29 Dannenberg C, Bierbach U, Rothe A, Beer J, Körholz D (2003) Ethanollock technique in the treatement of bloodstream infections in pediatric oncology patients with broviac catheter. J Pediatr Hematol Oncol 25: 616-621.

30 Takla TA, Zelenitsky SA, Vercaigne LM (2007) Effect of ethanol/ trisodium citrate lock on microorganisms causing hemodialysis catheter-related infections. J Vasc Access 8(4): 262-267.

31 Ackoundou-N'guessan C, Heng AE, Guenu S, Charbonne F, Traore O, et al. (2006) Ethanol lock solution as an adjunct treatment for preventing recurrent catheter-related sepsis--first case report in dialysis setting. Nephrol Dial Transplant 21(11): 3339-3340.

32 Takla TA, Zelenitsky SA, Vercaigne LM (2008) Effectiveness of a 30\% ethanol/4\% trisodium citrate locking solution in preventing biofilm formation by organisms causing haemodialysis catheter-related infections. J Antimicrob Chemother 62(5): 1024-1026.

33 Balestrino D, Souweine B, Charbonnel N, Lautrette A, Aumeran C, et al. (2009) Eradication of microorganisms embedded in biofilm by an ethanol-based catheter lock solution. Nephrol Dial Transplant 24(10): 3204-3209.

34 Betjes MG, van Agteren M (2004) Prevention of dialysis catheterrelated sepsis with a citrate-taurolidine-containing lock solution. Nephrol Dial Transplant 19(6): 1546-1551.

\section{Your next submission with Juniper Publishers will reach you the below assets}

- Quality Editorial service

- Swift Peer Review

- Reprints availability

- E-prints Service

- Manuscript Podcast for convenient understanding

- Global attainment for your research

- Manuscript accessibility in different formats

( Pdf, E-pub, Full Text, Audio)

- Unceasing customer service

Track the below URL for one-step submission https://juniperpublishers.com/online-submission.php 